\title{
Las restauraciones de 1903 y 1939 de la Basílica de Santa María de Elche. Incorporación de nuevos sistemas constructivos
}

\author{
Y. Spairani-Berrio, S. Spairani-Berrio, \\ D. Torregrosa-Fuentes, J. A. Huesca-Tortosa \\ Universidad de Alicante
}

RESUMEN

Este trabajo analiza las restauraciones de la Basílica de Santa María de Elche durante el siglo $\mathrm{XX}$ incluyendo las causas que provocaron dichas intervenciones. Este monumento alberga la representación del "Misteri" representación sacro-lírica catalogada como Patrimonio Inmaterial de la Humanidad. Los terremotos de 1746 y 1829 aumentaron los daños estructurales que ya presentaba el edificio desde su construcción. En la restauración realizada entre 1903 y 1907 por el arquitecto Marceliano Coquillat i Llofriu se sustituyó la cúpula y cubierta introduciendo el hierro en sus nuevas estructuras. Se convirtió en una de las primeras obras de restauración monumental del levante español donde se han empleado estructuras mixtas de hierro y ladrillo. El incendio de 1936 provocó graves daños dando lugar a otra gran restauración dirigida por Antonio Serrano Peral quien introdujo atados en la base de la cúpula y sustituyó las bóvedas de la nave y crucero.

\section{PALABRAS CLAVE}

Basílica Santa María de Elche; Restauración arquitectónica; Bóveda tabicada armada; Marceliano Coquillat i Llofriu, Antonio Serrano Peral.

The 1903 and 1939 restorations in the Basilica de Santa Maria of Elche. Incorporation of new construction systems.

\section{ABSTRACT}

This paper analyses the restorations of the Basilica de Santa Maria of Elche including the causes of these interventions. At this monument the "Misteri" listed as an inmaterial heritage of humanity is representation. The earthquakes of 1746 and 1829 caused severe structural damage. In the restoration carried out between 1903 and 1907 by the architect Marceliano Coquillat i Llofriu the dome and roof was replaced introducing iron into its new structures, making them one of the first monumental restoration works of the Spanish east where mixed iron and bricks vaults structures have been employed. A 1936 fire also generated serious problems in the building that forced another major restoration by Antonio Serrano Peral. Reinforced concrete were used in these works creating a tied and replaced the vaults of the nave and transept.

\section{KEYWORDS}

Basilica Santa María of Elche; Architectural restoration; Brick vault with metal structure; Marceliano Coquillat i Llofriu, Antonio Serrano Peral. 


\section{Introducción}

La Basílica de Santa María está situada en el centro de la que fuera primera villa murada de Elche y forma junto a la Calahorra y el Palacio de Altamira un conjunto histórico-artístico. Este Bien de Interés Cultural alberga la representación sacro-lírica del Misteri o Festa d'Elx declarada como Patrimonio Intangible de la Humanidad.

La Basílica está ejecutada con fábricas de sillería calcarenítica sin revestir tanto en su interior como en el exterior. Su construcción se realizó en varias fases dilatándose a lo largo de 111 años terminándose en 1784 con la ejecución de la Capilla de la Comunión.

La iglesia presenta planta de cruz latina y nave central dividida en cuatro tramos con capillas laterales entre contrafuertes y comunicadas entre sí. Su gran cúpula es ligeramente apuntada. Las bóvedas de la nave central y transepto son de cañón con lunetos. El presbiterio con semicúpula está rodeado por una girola que da paso a la capilla de la Comunión. El trazado de esta última es en planta de cruz griega cubierta por una magnífica bóveda vaída de construcción pétrea y con esviaje. Junto a la capilla se levantan las dependencias de la sacristía que, con una escalera volada de espléndida estereotomía pétrea, da acceso a la planta de tribunas. Este último espacio está diseñado para albergar un mayor aforo durante la celebración del Misteri. Su gran portada barroca, obra de Nicolás de Bussy, junto a algunos ornamentos interiores han provocado que se catalogue a este edificio como de estilo barroco valenciano, aunque la concepción del espacio es más propia del renacimiento.

Por otro lado, es un hecho que los avances en construcción van ligados al empleo de nuevos materiales. Esta premisa también es válida, aunque con matices, en el caso de la restauración arquitectónica. Al analizar las diferentes teorías del restauro y criterios de intervención a lo largo de la historia, se observa que las innovaciones en materiales y tecnologías siempre se han puesto al servicio de la restauración arquitectónica. En el siglo XX aparecen las diferentes cartas de restauración con recomendaciones en cuanto a criterios y técnicas de intervención más concretas ${ }^{1}$. Se redactan documentos que recogen directrices para
la conservación del Patrimonio destacando la Carta de
En la época en la que intervino el arquitecto Marceliano Coquillat i Llofriu en la Iglesia de Santa María estaba en auge la denominada "restauración científica" que presentaba dos vertientes un tanto diferenciadas como eran: "la restauración histórica" propugnada por Luca Beltrami y la "restauración moderna" de Camilo Boito ${ }^{2}$. Ambos arquitectos italianos afrontaron la problemática de la intervención en el patrimonio ${ }^{3}$.

Luca Beltrami tuvo que enfrentarse al colapso del "campanile" en la plaza de San Marcos de Venecia tras su colapso de 1902. Reconstruyó el edificio partiendo de documentación existe y atendiendo al requerimiento de la sociedad italiana que decidió que se reconstruyera "dov'era, com'era" "donde estaba, como era". Este arquitecto también reconstruyó el Palacio de los Sforza en Milán basándose en grabados de Filarete.

Camilo Boito, crítico del arte además de arquitecto, presentó una actitud más moderna y conciliadora entre las "corrientes no intervencionistas" de Ruskin y la "Restauración en estilo" de Viollet-le-Duc. Boito estableció criterios de intervención en patrimonio mediante 7 premisas que posteriormente serian base de la Carta de Atenas de 1931.

En la intervención que efectuó Coquillat en la iglesia de Santa María encontramos alguna coincidencia con premisas de Camilo Boito como: "la introducción de materiales nuevos con distinción de los antiguos" y "notoriedad visual de la intervención”. Se modificaron la estructura y el aspecto exterior de la cúpula cambiando incluso el tipo de tejas. También documentó la intervención junto al historiados Pere Ibarra, con descripciones y fotografías y la publicación del proyecto.

Posteriormente figuras relevantes en la restauración arquitectónica como Gustavo Giovannoni, Cesare Brandi en Italia, o Leopol-

Atenas para la restauración de monumentos históricos 1931, la Carta del Restauro, la Carta de Cracovia, y la Declaración de Amsterdan. ESBERT, Rosa María y LOSADA, José María. "Criterios de Intervención en materiales pétreos". Revista del Instituto de Patrimonio Histórico Español, 2, Oviedo, 2003.

2 BOITO, Camilo. Restauraciones en la arquitectura. Diálogo en primer lugar, en cuestiones prácticas de Bellas Artes, Milán, 1893. También en el nuevo y el viejo en la arquitectura, una antología editada por MA Crippa, Milán, Jaca Book, 1989, pp. 107-126.

3 RIVERA, Javier. De varia restauratione. Teoría e historia de la restauración arquitectónica. Madrid. 2008. 
do Torres Balbás en España avanzaron en las "Teorías del Restauro" marcando el contexto en el que trabajó el arquitecto ilicitano Antonio Serrano Peral ya a mediados del siglo XX. En esta época, marcada también por las carencias de la posguerra, seguían vigentes las premisas de Camilo Boito además de contar ya con la Carta de Atenas de 1931 y la Ley de 1933 sobre Patrimonio Histórico.

En la actualidad antes de introducir un nuevo material o sistema constructivo en un edificio histórico debe haber sido evaluado previamente. Así lo recomiendan los diferentes organismos que tutelan y velan por la conservación del patrimonio edificado ${ }^{4}$.

La incursión del cemento portland en construcción hizo que se sustituyese de forma masiva el empleo de la cal, e incluso del yeso, contagiándose dicha práctica también a la restauración arquitectónica. Esto estaba motivado fundamentalmente por la mayor resistencia mecánica del cemento frente a la cal y el yeso, atendiendo a las bondades del nuevo material, aunque no siempre acertadas. Esto provocó que durante casi todo el siglo XX la cal dejase de ser el aglomerante principal en muchas restauraciones del patrimonio edificado. A finales del siglo se retomó su uso tras detectar lesiones en edificios históricos generadas por el mal uso de cementos portland. Esto se debe principalmente a la diferencia de comportamiento en cuanto a las propiedades físicas y mecánicas respecto de las fábricas sobre las que se ha implementado. Por otro lado, se producen eflorescencias en las fábricas sobre las que se ha colocado cemento portland, por migraciones de sales o reducción de la transpirabilidad de las fábricas.

La introducción de tirantes metálicos para absorber los empujes en arcos y bóvedas se extendió con gran rapidez mejorando el comportamiento mecánico de los edificios históricos. Las uniones roblonadas implicaban que

\footnotetext{
UNE-EN 16096:2016. Conservación del patrimonio cultural. Inspección del estado e informe de patrimonio cultural construido. Asociación Española de Normalización y certificación, Madrid, 2016.

UNE-EN 16085:2014. Conservación del patrimonio cultural. Metodología para la toma de muestras de materiales del patrimonio cultural. Asociación Española de Normalización y certificación, Madrid, 2014.

UNE-EN 16515:2016. Conservación del patrimonio cultural. Líneas directrices para caracterizar la piedra natural utilizada en el patrimonio cultural. Asociación Española de Normalización y certificación, Madrid, 2016.
}

los entramados no tuvieran continuidad para crear verdaderos atados de todo el conjunto del edificio. Además, los forjados se apoyaban simplemente sobre vigas o cerchas metálicas y no rigidizaban transversalmente. La estructura de la cubierta de la nave de la Basílica de Santa María es un ejemplo de esta tipología.

\section{Metodología}

La metodología seguida en la realización del presente trabajo corresponde con las directrices generales marcadas hace décadas por Piero Sanpaolesi, y que siguen vigentes en la actualidad. En su "Discorso sulla metodologia generale del restauro dei monumento" ${ }^{5}$, Sanpaolesi propone que los estudios previos deben tener tres grandes fases:

a) Análisis directo, aquel que puede realizarse en contacto con la obra construida.

b) Análisis indirecto, que debe hacerse mediante el estudio de documentación de archivos, bibliotecas y otras fuentes.

c) Cada monumento requiere un tratamiento individualizado.

Siguiendo dichas recomendaciones, las de los autores y organismos encargados de la tutela del patrimonio ${ }^{6}$ y las Normas UNEEN 16085:2014 y UNE-EN 16515:2016², se ha estudiado el edificio in situ. Para ello se ha realizado su reconocimiento arquitectónico y constructivo por un lado y la lectura de los paramentos por otro. Además, se ha completado su estudio con la toma de muestras de materiales de las diferentes fases constructivas. Por último, se ha registrado el edificio empleando técnicas de escaneado láser y fotogrametría, plasmando la geometría de la Basílica en planos de plantas, secciones y alzados. La nube

\footnotetext{
SANPAOLESI, Piero. Discorso sulla metodologia generale del restauro dei monumenti.

6 AZCÁRATE, Agustín. El análisis estratigráfico en la restauración del patrimonio construido. 51-64 pp. CABALLERO, Luis. LATORRE, Pablo. "La importancia del análisis estratigráfico de las construcciones históricas en el debate sobre la restauración monumental". Informes de la Construcción, 46, 5-18pp. GONZÁLEZ, Antoni. La restauración objetiva.

7 UNE-EN 16085:2014. Conservación del patrimonio cultural. Metodología para la toma de muestras de materiales del patrimonio cultural, opus cit.

UNE-EN 16515:2016. Conservación del patrimonio cultural. Líneas directrices para caracterizar la piedra natural utilizada en el patrimonio cultural, opus cit.
} 
de puntos del edificio, obtenida por el escaneado láser, ha permitido además cuantificar las deformaciones existentes con gran precisión. Cada caso requiere un estudio singu$\operatorname{lar}^{8}$ debiéndose acometer siempre por equipos multidisciplinares.

En la fase de documentación se han vaciado varios archivos consultando fuentes originales tales como los libros de fábrica del Archivo de la Basílica de Santa María o protocolos notariales depositados en el Archivo Histórico Municipal, entre otros.

\section{Evolución constructiva}

Era práctica habitual en las construcciones antiguas reciclar materiales y aprovechar parte de las estructuras. Las edificaciones no siempre se demolían hasta la cota cero, por ello es necesario conocer cómo fueron esos templos anteriores al actual. Este análisis además permite relacionar problemas estructurales de los templos anteriores con los movimientos activos detectados al realizar el estudio-diagnóstico del estado actual de la Basílica.

\subsection{Los edificios anteriores}

No existen demasiados datos documentales sobre las anteriores construcciones. Respecto al primer edificio se sabe que en 1265 se bendice la primera iglesia cristiana tras la conquista de la Vila de Elche por el rey Jaime $\mathrm{I}^{9}$ quien ordenó transformar la mezquita en iglesia para el culto católico. Tras el derribo en 1334 de la mezquita se comenzó la construcción de una nueva iglesia gótica, de la que se sabe que en 1384 se estaba construyendo su último arco. Este segundo edificio desaparece sobre $1492^{10}$.

Respecto al edificio de época renacentista, y anterior al actual, se sabe que Julián de Alamíquez estuvo al frente de las obras entre 1555

8 FERNANDEZ, Antonio. "Reforma y rehabilitación del café Dindurra de Gijón”. Liño: Revista Anual de Historia del Arte, 22.

9 IBARRA, Pedro, Historia de Elche.1895. JAÉN, Gaspar. La Vila $i$ el Raval d' Elx: arquitectura $i$ urbanisme, Instituto de Cultura Juan Gil Albert, Alicante, 1999. RAMOS, Alejandro. Historia de Elche.

10 NAVARRO, Rafael. Los arquitectos del templo de Santa María de Elche. Confederación Española de Cajas de Ahorro. Alicante, 1980, 142pp y 1563. Esta tercera iglesia se terminó en 1566, y se puede asegurar que al menos tenía cuatro tramos, presbiterio y torre, ya que según asegura Castaño ${ }^{11}$ dicha iglesia tenía cuatro capillas laterales a cada lado. Estos datos son significativos porque se han hallado vestigios de ese edificio en la Basílica actual.

Entre la fecha de acabado del templo renacentista y 1642 hay un gran vacío documental. Según indican los libros de fábrica, el edificio tenía continuos problemas de goteras. ${ }^{12}$ Es significativo, para comprender como colapsó dicho edificio, que en 1647 se solicitara una inspección de los daños que presentaba el templo. ${ }^{13}$

El 30 de mayo de 1672 colapsaron parcialmente las bóvedas de la iglesia estando el arquitecto Francisco Verde inspeccionando el estado del edificio. De la descripción en los "Papeles curiosos" ${ }^{14}$ recopilados por Pere Ibarra se desprende que se derrumbaron parte de las bóvedas sin afectar al altar mayor ni al presbiterio. Esta es la fecha que hasta el momento aparece en todos los documentos como el final del edificio renacentista. Sin embargo, ese edificio no llegó a derribarse al completo, como se desprende de la investigación realizada por los autores de este trabajo.

\subsection{El edificio actual}

La Basílica la traza el arquitecto Francisco Verde a quien se le encarga la planta y sección el 8 de marzo de 1673 tomando como referencia la Iglesia de San Nicolás de Alicante, por imperativo de la parroquia, según señala $\mathrm{Na}-$ varro ${ }^{15}$.

Francisco Verde dirige las obras durante un año hasta 1674, fecha en la que fallece haciéndose cargo de las obras el arquitecto Pedro Quintana. En los cuatro años que está al frente de la obra, hasta su fallecimiento en 1678, se

${ }^{11}$ CASTAÑO, Joan. (1988). "Algunos datos sobre el tercer templo de Santa María de Elche (1492? -1672)”. Pobladores de Elche, 10, Elche, 1988, pp.79-89.

12 Archivo de la Basílica de Santa María de Elche [ABSME], Libros de Fábrica (1569-1599) (sig. 151/1).

13 ABSME, Llibre de la Fàbrica de Senta Maria de la Vila de Elig (1592-1699) (Sig. 151/2), acta del 26-12-1647 (Véase la edición realizada por CASTAÑO, Joan i MAS, Antonio, Universidad de Alicante, Alicante, 2015).

14 IBARRA, Pedro. Papeles curiosos. Archivo histórico Municipal de Elche, 1892.

15 NAVARR0, Rafael. Los arquitectos del templo, opus cit. 
levantan las fábricas de las capillas laterales siguiendo lo proyectado por Verde.

En 1680 Nicolás de Bussy realiza la Portada de San Agatángelo y la Portada Mayor que se bendice en 1682. Juan Fauquet i Verde aparece dirigiendo las obras de la Basílica desde 1681 hasta 1719, convirtiéndose en el arquitecto responsable de la mayor parte de la construcción del templo. Hecho que se reivindica en este artículo.

En 1686 se bendice la nave central de la Basílica de Santa María, estableciéndose así una primera fase constructiva del templo actual, coincidiendo en planta con las tres edificaciones anteriores. Las obras continúan posteriormente con la construcción del crucero y sacristía ampliando así el espacio respecto a los templos predecesores.

Se ha localizado documentación en el Archivo histórico de Elche que recogen pagos a Juan Fauquet por jornales y piedra de Les Salinetes en Elda para la construcción de la escalera y una portada del crucero $^{16}$. Este hallazgo pone de manifiesto la fecha y materiales empleados para la ejecución de la escalera y le da la autoría de la portada del órgano por semejanza de labra en los detalles de su factura. La magnífica estereotomía que presenta la escalera de bóveda pétrea ubicada en la sacristía recuerda a la del Colegio Santo Domingo de Orihuela obra de Joan Anglés. Edificio en el que trabajó Verde y que le debió servir de modelo.

En 1727 Fray Francisco Raymundo terminaría la cúpula. Posteriormente se construye el presbiterio. Desde ese mismo momento el edificio tuvo problemas estructurales ya que aparecen varios informes donde se mencionan grietas preocupantes y caída de piedras, incluso algún dictamen amenazaba ruina. Tras varios informes, el arquitecto Marcos Evangelio fue designado para la realización de un reconocimiento definitivo, y posteriormente como redactor del proyecto de reparación y director de las obras en 1759.

Marcos Evangelio comenzó la construcción de la actual Capilla de la Comunión. Estudios recientes ${ }^{17}$ han permitido localizar en la Sierra

16 Archivo Histórico Municipal de Elche [AHME], protocolo notarial del 21 de julio de 1758. (Sig. 955). Folio 31

17 SPAIRANI, Yolanda; GARCÍA DEL CURA, María Ángeles; BENAVENTE, David; LOUIS, Miguel; PRADO, Raúl; MARTÍNEZ, Javier; CUEVAS, Jaime. "Estudio de del Ferriol canteras empleadas en las fábricas de Santa María concluyendo además en dicho trabajo que la piedra empleada en la Capilla es igual a la de La Dama de Elche.

En 1763 se documenta la finalización de las nuevas bóvedas de la iglesia sustituidas por Marcos Evangelio, y que la Capilla de la Comunión se levantaba unos 20 palmos. También se indica que los cimientos de la pared que da al sur se tuvieron que reforzar varios metros en la cimentación por estar encima de una antigua acequia. Estos datos son significativos para comprender posibles causas de movimientos estructurales presentes actualmente en el edificio en la zona sur y que corresponden a asientos diferenciales. Tras el fallecimiento de Marcos Evangelio se le pagan unos planos a Lorenzo Chápuli por el remate de la Capilla de la Comunión, pero no se llegan a ejecutar ya que finalmente se le encarga a José Gonzálvez de Coniedo el diseño y ejecución de las bóvedas de la Capilla de la Comunión ${ }^{18}$.

El 2 de octubre de 1784 fue bendecida la Iglesia y la capilla de la comunión. El 3 de octubre de 1789 es elevada al rango de Insigne.

\section{Las restauraciones del siglo $\mathrm{XX}$}

Como ya se ha indicado, el templo barroco ha tenido numerosos problemas de estabilidad desde la finalización de la pesada cúpula pétrea, a ello se le añade que el edificio ha sufrido daños estructurales provocados por los terremotos de 1746 y 1829 y un gran incendio en 1936. Por otro lado, el deterioro provocado por agentes meteorológicos y la contaminación ha sido especialmente virulento en el caso del material pétreo empleado en la construcción de este edificio. Todo ello ha propiciado necesarias y continuas intervenciones en el templo que han ido modificando no sólo su aspecto original sino también los sistemas constructivos y estructurales.

canteras históricas de Ferriol. Valoración de su utilización como piedra de sustitución en Sta María de Elche". Euro-American Congress REHABEND 2016. Burgos, 68-75pp.

18 DELICADO, Francisco Javier. "El arquitecto, maestro tallista y pintor José Gonzálvez de Coniedo, un artífice de la segunda mitad del siglo XVIII en tierras meridionales valencianas y zonas de influencia”. Archivo de arte valenciano, 83, 2002, 45-52pp. 


\subsection{La restauración a cargo de Marceliano Coquillat i Llofriu, 1903-1907}

El arquitecto ilicitano Marceliano Coquillat i Llofriu fue el encargado de proyectar las obras de restauración que necesitaba el edificio en 1902. Este arquitecto trabajaba en el Ayuntamiento de Barcelona, hecho que motivó que las obras las llevase a distancia, sirviéndose del envío de misivas principalmente al erudito historiador Pere Ibarra, familiar suyo muy preocupado por la conservación del templo. También se carteó con los párrocos y con algunos encargados de las obras. Estas 327 cartas las recogió Pere Ibarra en un manuscrito inédito custodiado por la familia de Serrano Peral ${ }^{19} \mathrm{y}$ cuya consulta ha sido básica para la comprensión de la gran restauración llevada a cabo a principios del siglo $\mathrm{XX}^{20}$.

Marceliano Coquillat trajo a Elche los sistemas constructivos y materiales que se estaban empleando en ese momento en la Barcelona modernista. Coquillat intervino en dicha ciudad reformando algunos edificios adaptándolos al gusto modernista del momento. En algunos casos introdujo además detalles de estilo neoclásico, ejemplos de sus actuaciones son la finca "Ca Gines$\operatorname{tar}^{21}$ o la "Casa Bonet” del Paseo de Gracia. En el año 1902 Lluís Domènech i Montaner comienza a trabajar en el Hospital de San Pau, obra que cuenta con una cúpula, mucho menor que la de Santa María, realizada con bóveda tabicada y tirantes circulares según indica Jerónimo Martorell ${ }^{22}$. Esta técnica constructiva es semejante a la empleada por Coquillat en Santa María.

19 Fue un Arquitecto muy importante para la ciudad de Elche como se muestra en Spairani, Silvia., Louis, Miguel, Spairani, Yolanda. Huesca, José Antonio. "La iglesia del Sagrado Corazón de Jesús en Elche. Un ejemplo de la introducción del hormigón en la arquitectura sacra”. Liño: Revista Anual de Historia del Arte, 22, 2016, 113-120pp. También JAÉN, Gaspar, “Antonio Serrano Peral, arquitecto: viviendas, fábricas, dotaciones", Festa d'Elx, 56, p. 69-94.

20 Archivo de los herederos de Antonio Serrano Peral, Reparación del templo de Santa María de Elche 19021907. Correspondencia coleccionada para su más fácil conocimiento. También GARCÍA, Juan José., NAVARRO, Rafael. y SERRANO, Antonio. "Las huellas del tiempo, construcción y restauración de la basílica de Santa María”. Publicación de la exposición Gráficas Estilo, Elche, 2011, 111pp.

21 LACUESTA, Raquel. Modernisme a l'entorn de Barcelona: Arquitectura i Paisatge. Diputació de Barcelona, 2006.

22 MARTORELL, Jerónimo. "Estructuras de ladrillo y hierro atirantado en la Arquitectura catalana moderna". Anuario: Asociación de Arquitectos de Cataluña, Barcelona,1910,119-146pp.
El arquitecto redactó un proyecto, que todavía se conserva, compuesto por las mismas partes básicas que en la actualidad contienen los proyectos de intervención en el patrimonio edificado, una memoria donde se recoge la historia del edificio, un diagnóstico del estado actual y unas propuestas de intervención valoradas y registradas en planos de planta, alzado y sección. Destacar que no se ejecutó casi nada de lo que había planteado en el documento de proyecto. De aquí la importancia de la existencia de documentación tanto gráfica como escrita aportada por el historiador Pere Ibarra quien escribió dos manuscritos describiendo las obras de restauración incluyendo numerosas fotografías ${ }^{23}$.

\subsubsection{Daños presentes en la iglesia en 1903}

Es necesario realizar un resumen de los daños que presentaba el templo en 1903. Según se deduce del proyecto de Marceliano Coquillat ${ }^{24}$, del estudio de los informes periciales y del análisis de las imágenes del templo anteriores a su restauración las principales lesiones eran:

1.- Arco toral que daba a la nave quebrado y flechado. Se había ensanchado su luz en 39 $\mathrm{cm}$, debido a la falta de resistencia de los estribos que tenían que absorber esos empujes.

2.- Cúpula con asiento y grietas como consecuencia de la elongación de la luz del arco toral que soporta la cúpula. Esto implicó la aparición de grietas pasantes en la cúpula, en las 4 pechinas y el tambor. Dicho asiento se ha cuantificado actualmente en $11 \mathrm{~cm}$ y queda reflejado en la sección A-A' de la fig.1.

3.- Estructura portante de las tribunas con asientos y deformaciones en arcadas entre contrafuertes y con grietas. Las grietas no coplanarias presentes en los contrafuertes corresponden a típicas deformaciones por sismo ${ }^{25}$.

4.- Arcos formeros deformados y con grietas.

23 Además del volumen citado en la nota 18, en el Archivo de los herederos de Antonio Serrano Peral se conserva también un segundo volumen manuscrito por P. Ibarra, titulado Reparación del templo de Santa María de Elche 1902-1907. Diario gráfico ilustrado con interesantes fotografías. Véase GUILABERT, Jerónimo. Las fotografias del historiador Pedro Ibarra y Ruiz. Cubicat, Elche, 2014.

24 GARCÍA NAVARRO, Juan. José. “La Restauración de la Basílica de Santa María de Elche de Marceliano Coquillat (1902-1906)" Revista Festa d'Elx. No57. 2013.

25 FRÍAS, Alfredo. et al. "Evaluación rápida de daños en emergencias. Protocolos de Activación y Actuación del Grupo de Evaluación de Daños”, Compobell, S.L, Murcia, 2015, 591pp. 


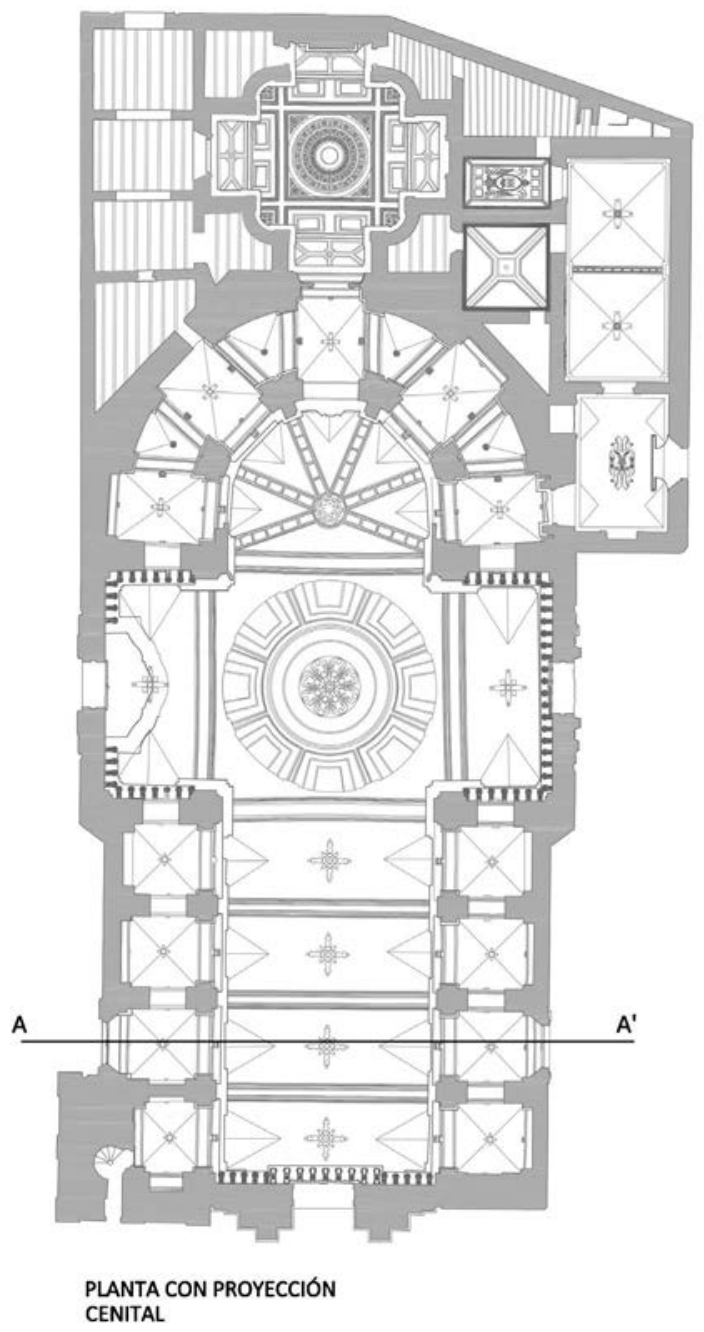

Fig. 1. Planta y sección A-A' del estado actual de la Basílica

\subsubsection{El proyecto}

El proyecto consta de 53 páginas incluyendo 6 fotografías y 4 planos. ${ }^{26}$ En la parte del proyecto denominada "Proyecto: su descripción” se plantean dos posibles soluciones, la primera, muy radical, consistiría en el derribo y reedificación completa de la iglesia, desde el ábside hasta la fachada principal, y la segunda se centraría en desmontar lo que realmente tenía peligro de derrumbe, la cúpula, parte del tambor, bóvedas y lunetos de la nave, y rehacerlos de nuevo con sistemas constructivos más ligeros, reforzando y atirantando los cuatro arcos torales. Tras cuantificar la primera solución

26 COQUILLAT Y LLOFRIU, Marceliano, Proyecto de reparación de la Insigne iglesia parroquial de Santa Maria de la ciudad de Elche, Barcelona, 1903.

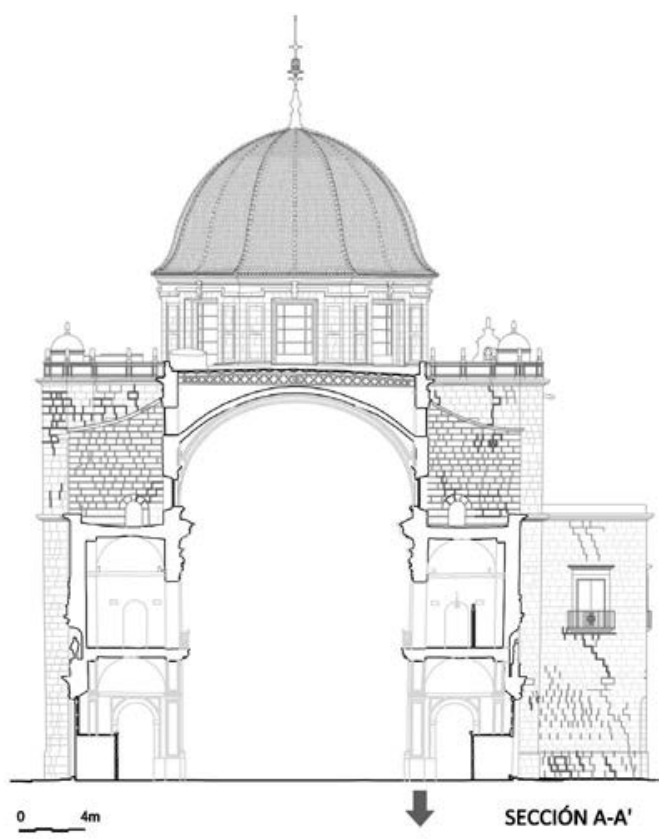

en un millón de pesetas y estimar un excesivo tiempo de ejecución, decide quedarse con la segunda propuesta.

Se describen las actuaciones a seguir según orden de ejecución, primero "Cimbrado de los cuatro arcos torales" acompañado de planos. La segunda operación era "Andamiaje superior $y$ apeo de la cúpula". La tercera operación proyectada era "Refuerzo de los arcos torales y sus apoyos", grafiado en plano. En este apartado se explicaba cómo se debían realizar unos refuerzos pareados a ambos lados de cada arco que nacían desde la base de las pilastras y que se proyectaba ampliar con piedra o ladrillo con unas dimensiones de $80 \mathrm{~cm}$ de ancho por $70 \mathrm{~cm}$ de saliente, que debían trabarse con las pilastras mediante el rebaje y encaje de los sillares existentes o ayudados de elementos metálicos empotrados, todo unido con mortero de ce- 
mento. Se proyectaba colocar unas estructuras metálicas a cada lado de los arcos, que se terminarian con ladrillos y mortero de cemento, y estuco imitando sillería, apoyados sobre esos recrecidos de las pilastras.

Reseñar que Coquillat en un mismo plano representaba la intervención (en la mitad derecha) y el aspecto que debería tener acabado (en la mitad izquierda).

La operación $\mathrm{n}^{\circ} 4$ era "Derribo de las bóvedas y arcos de la nave". Se debía reaprovechar la cimbra del arco toral del presbiterio para colocar un andamiaje en la cubierta sin apoyarse sobre ella, haciéndolo sólo en los muros y antepechos laterales. Comenzando por la zona pegada a la fachada principal se debían ir demoliendo la cubierta y las bóvedas. Tras el derribo se deberían ejecutar los nuevos arcos con estructura metálica y sobre estos un entramado de madera que soportaría la cubierta plana. Las bóvedas y lunetos nuevos deberían ejecutarse con tres hojas de rasillas cerámicas.

Operación no 5, "Reparación del tambor y reconstrucción de la cúpula". Se debía reparar el tambor, levantando las cornisas y dinteles "quebrantados o poco sólidos", reforzando dichos dinteles con dos o tres viguetas de hierro. Coquillat recalca la importancia de no romper sillares con molduras o esculturas.

La cúpula nueva, según indica el arquitecto, podría ser de tres gruesos de rasilla, con doble bóveda, de forma que quedase un espacio hueco entre las dos, disponiendo de dos o tres zunchos sencillos de hierro que impidiese cualquier deformación horizontal. La bóveda interior se indica que podría ser construida con el sistema Monnier de cemento armado, y explica: "...que es un entramado de varillas de hierro macizado con cemento". Posteriormente puntualiza que era un sistema más caro que la bóveda tabicada pero más "sólido". También señala Coquillat que fuese cual fuese la solución final a ejecutar, se debía mantener el mismo aspecto desde el interior de las bóvedas. El exterior de la cúpula se debía revestir con "tejas planas barnizadas en forma de escamas", pudiendo tener diferentes tonos y formar dibujos. Se proponía poner caballetes para dar el aspecto ochavado.

Operación $\mathrm{n}^{\circ}$ 6, "Reparaciones secundarias, macizado de juntas abiertas y grietas; restauraciones". En este apartado se especificaban las operaciones de restauraciones de antepechos de las ventanas del tambor, pechinas, sellado de grietas en las bóvedas del crucero y restauraciones de zonas puntuales y zócalos. El proyecto contenía otro apartado denominado "Procedimiento que debía seguirse para la ejecución de las obras y tiempo que probablemente se emplearía para su realización", especificando que se debía seguir la legislación vigente. Coquillat hace en este punto una interesante reflexión sobre la dificultad de valorar los costes de ejecución con un presupuesto cerrado, llegando a la conclusión que se debía ejecutar por administración siendo consciente de la dificultad de valorar económicamente este tipo de obras. Establece un plazo mínimo, suponiendo que trabajasen bastantes obreros, de entre $10 \mathrm{y}$ 12 meses.

El presupuesto es el capítulo final, previsto de 132.818,40 pesetas. Los epígrafes son, como solía hacerse en esa época, generalistas y poco detallados. Respecto al cemento se presupuesta cemento rápido y cemento portland inglés además de yeso negro.

\subsubsection{Descripción de las obras}

Las obras se iniciaron en mayo de 1903 y duraron cuatro años. Primeramente, se apuntalaron los cuatro arcos torales con cimbras de madera para poder desmontar la pesada cúpula de piedra con seguridad y volver a construir la nueva. Durante las obras al revisar las bóvedas y los arcos diafragma, se descubre que el arco central estaba muy dañado. Se intervinieron 14 dovelas.

Posteriormente se trabajó en la cubierta por tramos comenzando desde los pies del Templo.

Se iba desmontando por tramos la antigua cubierta que era ligeramente inclinada y cuya formación de pendientes estaba ejecutada mediante pesados tabiquillos de unos $10 \mathrm{~cm}$ de espesor de mampostería, con revoltón también pétreo (Fig. 2). Se construyó una nueva cubierta plana, de forjado de viguetas metálicas y revoltón cerámico que se apoyaba sobre 7 cerchas metálicas roblonadas. Se colocó una sobre el arco toral y las otras a cada lado de los tres arcos diafragma de la nave.

Esa nueva solución constructiva aligeró las cargas producidas por la cubierta, pero modificó su forma de transmisión a los muros de carga. Se pasó de un reparto continuo desde las bóvedas a cargas puntuales de las vigas, por ello Coquillat reforzó los muros de fábrica de mampostería adosando una hoja de fábrica de 


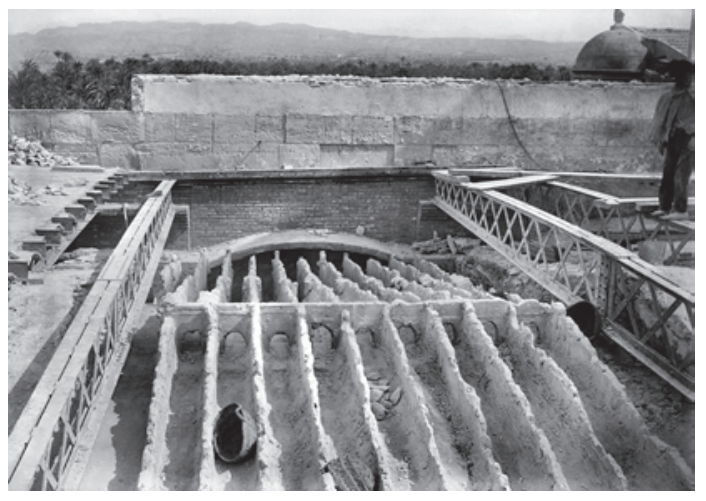

Fig. 2. Obras de sustitución de la cubierta (1904). Fotografía realizada por Pere Ibarra. Propiedad de la familia Serrano Peral y digitalizado por Jerónimo Guilabert.

ladrillo macizo y creando pilastras con ménsulas de ladrillo donde apoyan las cerchas. Estas pilastras se arriostraron lateralmente con arcos tabicados, tal y como puede apreciarse en el fondo de la Fig. 2. Las cerchas metálicas presentan una curvatura superior a modo de "arco rebajado" que le proporciona una mayor resistencia a flexión, menor deformación por flecha y sirve además para propiciar la pendiente de la cubierta plana tirando el agua hacia los laterales de la nave. Esta estructura es semejante a la Fig. 6 que aparece en la lámina XIV del Atlas del Tratado de Construcción Civil de Florencio Ger y Lobez de $1898^{27}$, aunque en dicha lámina la cercha es de sección constante. Las estructuras metálicas fueron realizadas por Juan Torra de Barcelona. Dada su gran longitud no se construyó de una sola pieza, por lo que los perfiles superiores e inferiores están unidos en la zona central.
La cercha está formada por $4 \mathrm{~L}$ de $90 \mathrm{~mm}$ de lado que aprisionan pletinas de $60 \mathrm{~mm}$ formando cruces unidas mediante roblones en el centro, en la parte superior e inferior.

La unión central se realizó mediante pletinas con roblones y refuerzos superior e inferior. Sobre dichas cerchas se colocaron vigas IPN 160, y apoyadas en el ala inferior de dichas viguetas un revoltón de rasillas cerámicas tomadas con yeso negro y sobre las mismas un relleno con morteros de cemento portland ingles formando el entrevigado. Dicha estructura servía de base a la cubierta plana acabada con baldosín catalán.

Posteriormente se desmontó la cúpula (Fig. 3). Según se documenta en las cartas de Pere Ibarra al llegar al metro de altura, respecto de la cornisa exterior, se encontraron un anillo perimetral de madera a modo de zuncho, dato que pone de manifiesto que cuando ejecutaron la cúpula a principios del siglo XVIII ya sabían de la necesidad de absorber los empujes en su parte inferior. En la misma misiva se indica también que el espesor de la cúpula era de $46 \mathrm{~cm}$.

En los documentos escritos por Pere Ibarra se refleja que durante las obras en febrero de 1905 Coquillat pensó en dos soluciones diferentes para la nueva cúpula, una empleando un armazón de hierro y bóveda de ladrillo y otra posible empleando cemento armado con varillas de hierro rematando la nueva cúpula, en cualquier caso, con tejas planas menos pesadas que las curvas. Estimaba que ambas soluciones eran mucho más ligeras pasando de los $400.000 \mathrm{Kg}$ a los $60.000 \mathrm{Kg}$. Finalmente optó por

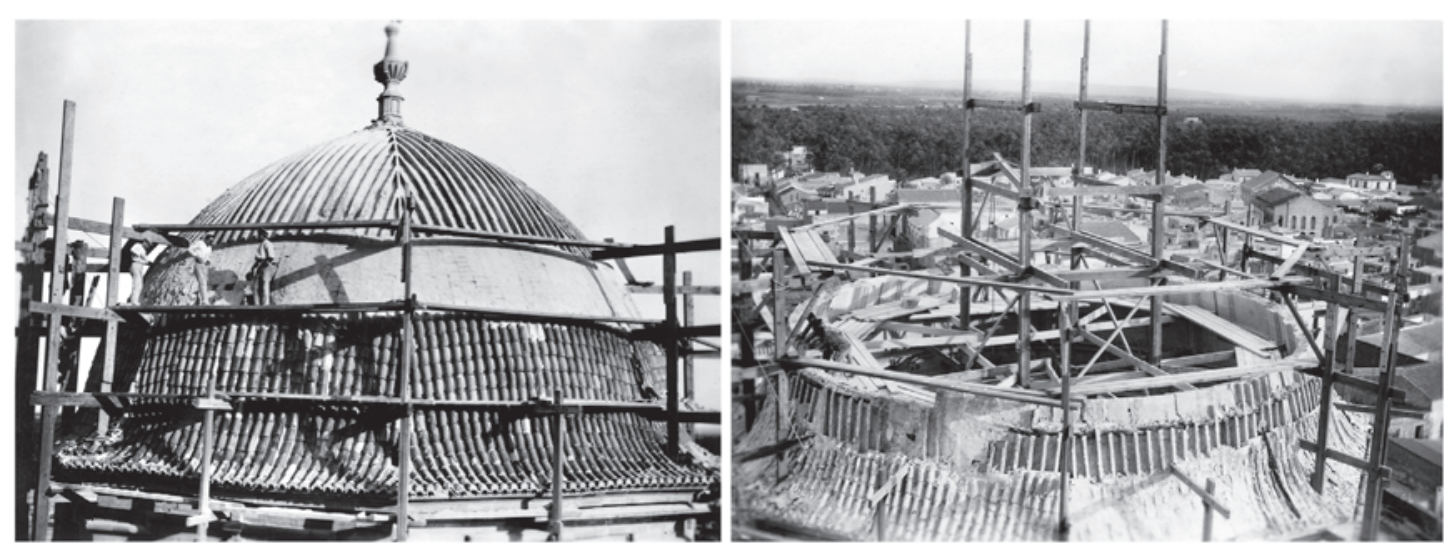

Fig. 3. Fase de desmonte parcial de la cúpula y del tambor. Fotografía realizada por Pere Ibarra 1905. Digitalizada por Jerónimo Guilabert.

27 GER, Florencio. "Atlas del Tratado de Construcción Civil”, La Minerva Extremeña, Badajoz, 1898, 69pp. 
la primera solución. La estructura metálica se fabricó también por Juan Torras en Barcelona.

El diseño es semejante al que aparece en la lámina XXIII del Atlas del Tratado de Construcción Civil de Florencio Ger y Lóbez de 1898 ya mencionado, concretamente coincide con la figura $n^{\circ} 1057$.

En marzo de 1905 los canteros desmontaron parcialmente el tambor en la zona noroeste justo en la parte que recae sobre el arco toral flectado. Se rehízo con fábrica hueca para reducir las cargas.

La estructura metálica está formada por 28 meridianos y 10 paralelos, con 14,54 metros de diámetro máximo en el paralelo inferior. Ese primer paralelo se apoya directamente sobre la cornisa de arranque de la cúpula y el último conforma un círculo central de unos 3 metros de diámetro atado por un aspa doble de perfiles en doble $\mathrm{T}$ (Fig. 4). Los meridianos van desde ese círculo superior hasta el primer paralelo, y están ejecutados con viguetillas doble $\mathrm{T}$ de $8 \mathrm{~cm}$. El segundo y tercer paralelo se arriostran por completo con pletinas en forma de cruz en cada uno de los trapecios formados entre meridianos y paralelos. Con el fin de arriostrar también a media altura del armazón metálico se crean 2 aspas con pletinas entre los paralelos $5^{\circ}$ y $6^{\circ}$.

Maclada con dicha estructura se ejecutó una bóveda tabicada con 4 capas de rasillas cerámicas. Coquillat consiguió así una construcción singular al entrelazar el armazón con las rasillas. La primera capa se tomó con yeso o con cemento rápido (ambos materiales aparecen en las mediciones y presupuestos) y con los ladrillos cerámicos dispuestos en plano con su mayor longitud en sentido horizontal, esta capa se apoyó en el interior del ala del perfil doble $\mathrm{T}$, la segunda capa también colocada en plano se tomó con cemento, pero con las rasillas dispuestas en vertical. La tercera capa se agarró también con cemento y con las rasillas en horizontal, en total estas tres capas coincidian con el alma de los perfiles doble $\mathrm{T}$. Posteriormente se colocó una cuarta capa exterior cubriendo exteriormente el armazón metálico. Se emplearon cementos de dos clases diferentes. La cúpula la realizaron operarios especializados venidos desde Barcelona.

El encuentro con el alero se ejecutó con dos hiladas de tejas curvas puesto que son capaces de absorber mejor el encaje de la forma trapezoidal y de fuerte cambio de pendiente en esa zona. Se colocaron dos niveles de limatesas. Las principales, que marcan el octógono con caballetes curvos vidriados con tejas de gran formato y dividiendo cada paño se colocaron otras tejas curvas más pequeñas.

Esto modificó el aspecto exterior de la cúpula, que pasó de tejas curvas a planas y de 8 paños a los 16 que se tiene en la actualidad. Coquillat en su proyecto había planteado colocar escamas vidriadas (habituales en el estilo modernista del momento en Cataluña), los ajustes económicos de las obras obligaron a modificar la idea original del arquitecto.

\subsection{La restauración de 1939 a cargo de Antonio Serrano Peral.}

El 20 de febrero de 1936, la iglesia de Santa María fue incendiada. El templo quedó muy dañado, por lo que necesitó una intervención. En 1939 se creó para ello la Junta restauradora del Misterio de Elche y de sus Templos que encargó a Antonio Serrano Peral el proyecto y dirección de las obras de restauración bajo su total responsabilidad. A partir de ese momento y hasta su fallecimiento en 1968 se convirtió en el arquitecto conservador de la Basílica, realizando varias intervenciones ${ }^{28}$.

Este arquitecto realizó numerosos y diferentes tipos de proyectos de arquitectura entre los que se encuentran iglesias, viviendas, edificios industriales o dotacionales entre otros ${ }^{29}$.

El incendio generó una enorme destrucción, agudizando problemas estructurales que venían desde antes, creando problemas nuevos y acabando prácticamente con toda la ornamentación interior de la iglesia tal y como atestigua la documentación fotográfica del archivo particular de Serrano Peral. Según indica Serrano Peral, en su proyecto de restauración de 1939, las bóvedas presentaban tales daños que se debían sustituir y algunos arcos también requerían sustituciones puntuales de dovelas. ${ }^{30}$ La temperatura que se alcanzó durante el incendio provocó en los sillares de piedra caliza

${ }^{28}$ GARCÍA, J. J., NAVARRO, R. y SERRANO, A. "Las huellas del tiempo, opus cit.

29 JAEN I URBAN, Gaspar. Antonio Serrano Peral (19071968). Arquitecto moderno heterodoxo. Actas del I Congreso nacional Pioneros de la arquitectura moderna española: vigencia de su pensamiento y obra. Madrid: Fundación Alejandro de la Sota, 2014. ISBN 978-84-697-0296-3, pp. 440-451 http://hdl.handle. net/10045/40864

30 SERRANO PERAL, Antonio, "Proyecto de restauración de la iglesia de Santa María de Elche”, Revista Nacional de Arquitectura, 37, 1945. 


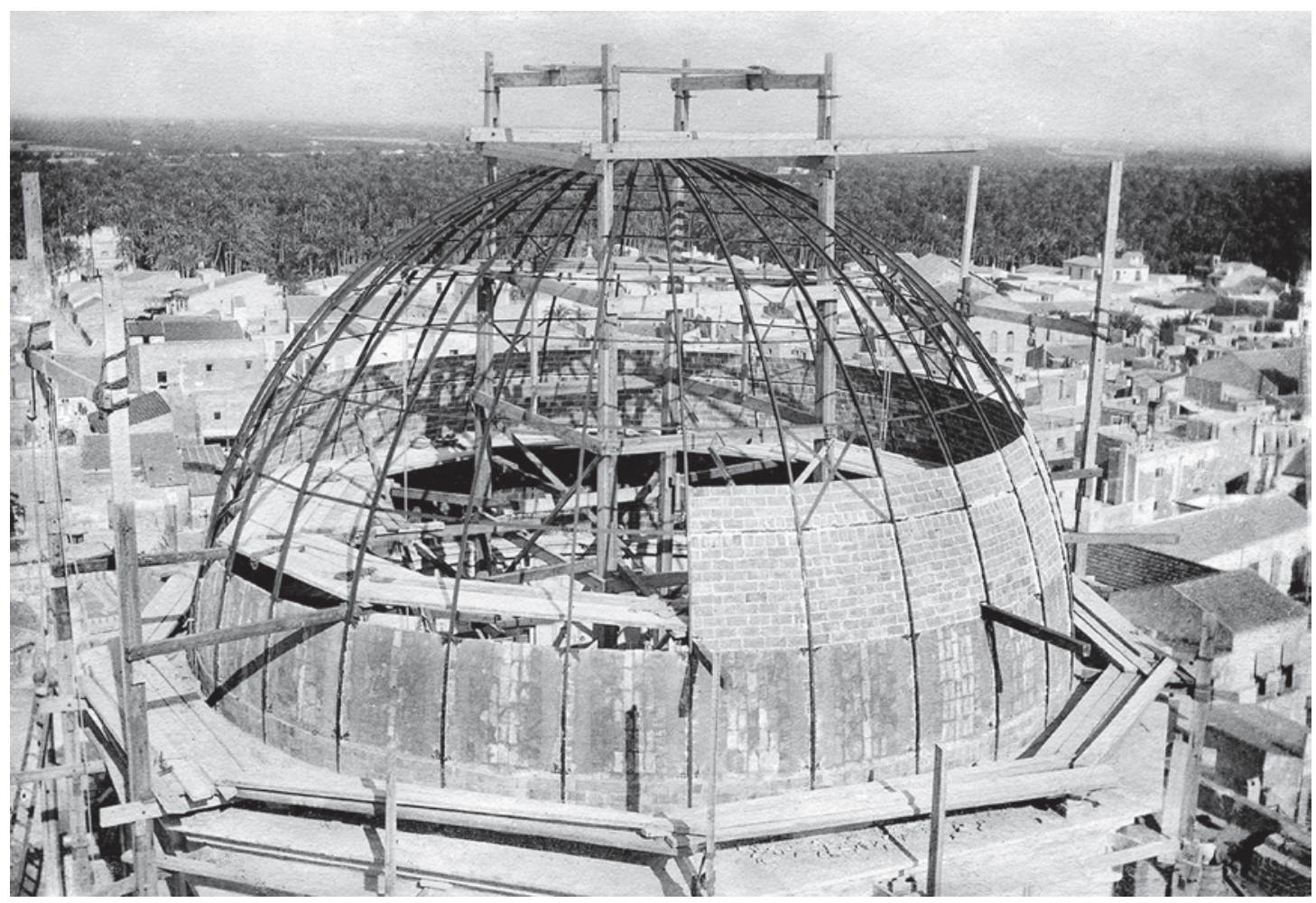

Fig. 4. Fase de reconstrucción de la cúpula. Fotografía realizada por Pere Ibarra 1905. Digitalizada por Jerónimo Guilabert.

costras superficiales por calcinación, las cuales provocaron a su vez una deslajación con pérdida generalizada del acabado superficial de los sillares, cornisas y tallas, además de dejar completamente ennegrecido el interior de la iglesia.

Las obras de restauración tras la guerra civil comenzaron, como se indicaba en el proyecto (que conservan sus descendientes), con la limpieza mecánica del interior de la iglesia. Simultáneamente se picó todo el estuco de yeso de la cúpula y se sustituyó por el actual realizado con mortero de cal y cemento, dejando un acabado completamente mimetizado con el resto de fábricas de piedra. Los arcos torales de la cúpula se reforzaron con hormigón armado, al igual que la cornisa de arranque de la cúpula. Se hicieron perforaciones en la sillería que forma el toro de la base del tambor en forma de "cola de milano" para crear un anclaje mecánico con el hormigón. Se colocaron armaduras y se creó un zuncho perimetral (Fig.5).

La bóveda del crucero sobre el órgano y la de la nave se desmontaron, y se sustituyeron por otras de sillería cogidas con mortero de cemento. La cubierta apoyada sobre estructura metálica realizada por Coquillat a principios de siglo también se intervino. Se sustituyó el forjado al completo debido a la corrosión de las viguetas metálicas, probablemente provocado por el contacto directo con los sulfatos, ya que la primera capa de rasillas del revoltón se recibió con yeso y la cubierta carecía de impermeabilización sufriendo numerosas filtraciones de agua. Serrano copió el sistema empleado por Coquillat, pero con una mayor luz inter-ejes de viguetas. $^{31} 32$

Antonio Serrano Peral intervino también en las cornisas exteriores del edificio además de repavimentar la Basílica con mármol blanco y negro según su propio diseño dejando su impronta en el Templo de una forma visible. Las losas de piedra que conformaban el pavimento original las reubicó en las aceras que rodean al edificio.

\section{Conclusiones}

La Basílica de Santa María de Elche ha tenido varias intervenciones a lo largo de su historia en las que se han sustituido sistemas

SERRANO BRU, Antonio, "Serrano Peral y Santa María de Elche: Análisis crítico de la restauración de 1939", Festa d'Elx, 56, p. 97-112. 


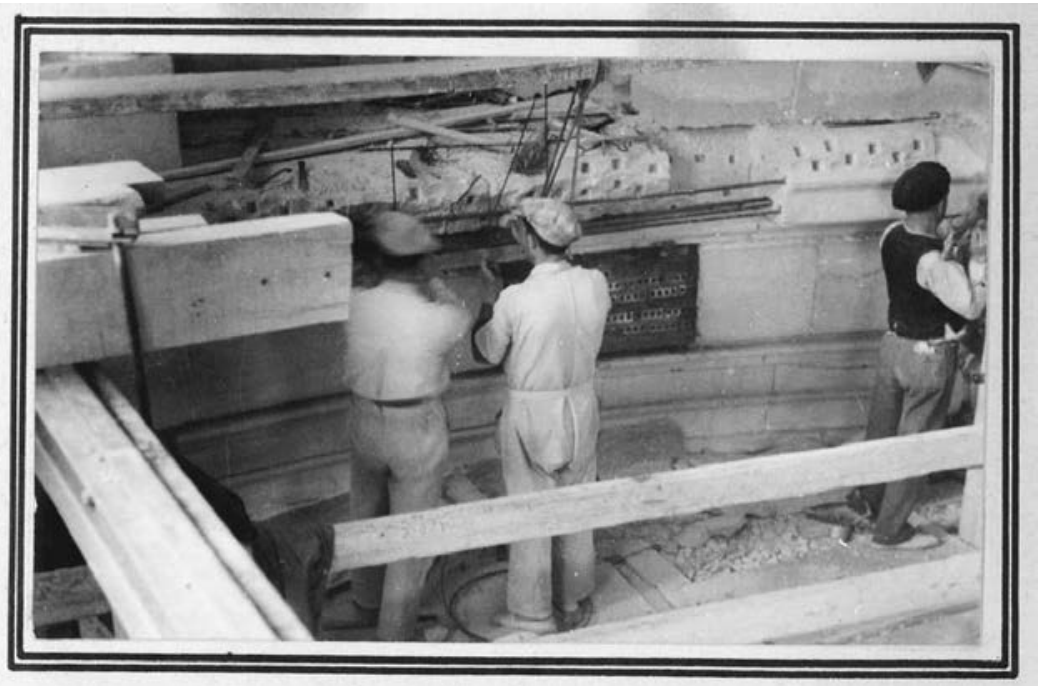

Fig. 5. Fotografía de la ejecución del zuncho en la base de tambor. Archivo particular de la familia Serrano Peral.

estructurales de fábrica en la cúpula y en las cubiertas por estructuras mucho más livianas.

Los estribos que soportaban los $400.000 \mathrm{Kg}$ de la cúpula de cantería construida a principios del siglo XVIII sufrieron deformaciones excesivas. Se produjeron vuelcos hacia el exterior del edificio, la cúpula se deformó por la elongación de la luz de los arcos torales manifestándose grietas y flechas tanto en la cúpula como en el tambor y las pechinas. A estos daños se sumó un asiento diferencial en los estribos situados en la zona sur y los daños por sismos.

La bóveda de la nave principal, ya sustituida en el siglo XVIII por Marcos Evangelio, presentaba daños a principios del siglo XX derivados de la pesada solución de cubierta de mampostería con tabiquillos como formación de pendiente, revoltón pétreo y cubierta inclinada a dos aguas y amplificados por el sismo de 1829.

El arquitecto ilicitano que trabajaba en el Ayuntamiento de Barcelona Marceliano Coquillat i Llofriu proyectó y dirigió en la distancia las obras de restauración con el propósito de aligerar y reparar el edificio. Aunque las obras ejecutadas difirieron notablemente de las soluciones proyectadas en los arcos torales, arcos formeros y cubierta, si se mantuvo su propuesta de introducir estructuras metálicas, aunque realizadas con un diseño diferente al propuesto en el proyecto de restauración.

Los arcos formeros se restauraron, pero no se desmontaron, se aligeró la bóveda de cañón al quitarle toda la cubierta anterior y crear una nueva más ligera con forjado de viguetas metálicas con revoltón de rasillas cerámicas apoyado sobre cerchas metálicas roblonadas. La cúpula nueva se realizó con estructura mixta de armazón metálico y bóveda tabicada.

El incendio de 1936 provocó graves daños en las bóvedas pétreas. El arquitecto Antonio Serrano Peral intervino en el edificio reconstruyéndolas con sillería caliza y mortero de cemento portland. En la base del tambor de la cúpula se introdujo un zuncho de hormigón armado para reforzar dicha zona frente a esfuerzos de tracción.

Todas estas restauraciones han modificado la construcción original de la Basílica de Santa María introduciendo materiales y sistemas constructivos propios del momento de cada intervención y bajo criterios aceptados como válidos en cada época.

\section{Agradecimientos}

A D. Antonio Serrano Brú por permitir consultar y utilizar documentos originales del archivo privado de D. Antonio Serrano Peral así como el uso de fotografías y el tiempo dedicado. A D. Juan José García Navarro por la información aportada. A D. Jerónimo Gilabert por permitir consultar y utilizar fotografías digitalizadas de Pere Ibarra. 